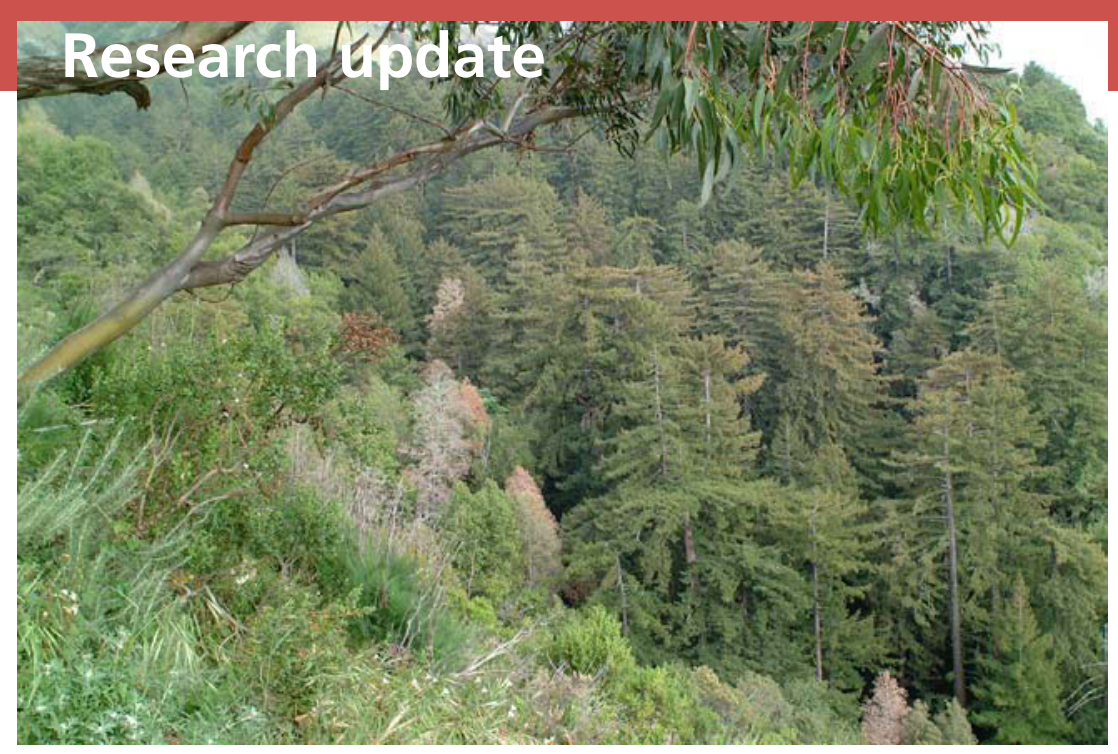

\title{
Promising treatment, control options for sudden oak death
}

In this Big Sur canyon sudden oak death has killed many tanoaks, while infected redwoods nearby still look healthy.

mately 40 adult oak trees throughout the natural range of coast live oak. When exposed to the pathogen, the size of cankers 3 weeks after inoculation was significantly different among individuals and ranged from 0.4 to 3.2 inches (10 to 80 millimeters).

Chemical treatments using nontoxic compounds known as phosphonates are routinely used in orchards to combat P. cinnamomi and have been applied successfully in the wild lands of Western Australia and Europe. In multiple controlled experiments by UC Berkeley Cooperative Extension scientists, in collaboration with UC Davis plant pathologist David Rizzo and farm advisors Steven Tjosvold and Pavel Svhira, phosphonates were successfully employed to prevent infection by $P$. ramorum on potted coast live oak trees, 9 to 15 feet tall with trunk diameters of 2 to 4 inches (see figure). When applied to adult trees in the field, the phosphonates also provided significant control and lesions were significantly smaller than in untreated controls.

Despite these promising results, Garbelotto warned, "The method of delivery of the compound, the timing and dosage must be studied before any treatment is evaluated by regulators and formalized for use."

While genetic resistance and chemical controls can provide useful, proactive tools for an integrated pest management approach, the scientists say that sanitation and spread control are still the most powerful methods to slow down sudden oak death. A series of studies done by the Garbelotto research group in collaboration with the California Integrated Waste Management Board showed that plant material infected by $P$. ramorum is noninfectious once properly composted. "If compost is not re-exposed to infection, it should be a viable way to reduce inoculum levels," Garbelotto says.

Researchers and policy-makers agree that sud-

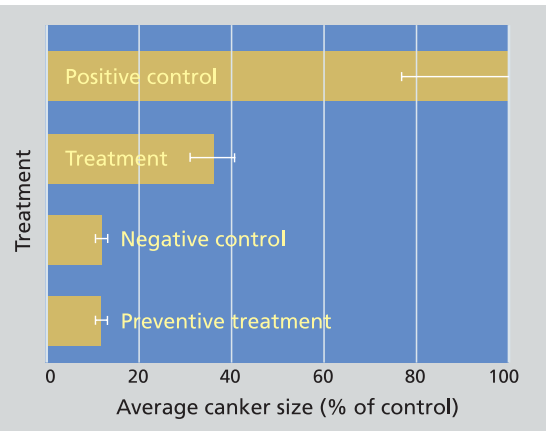

Effect of phosphonate treatment on canker size in coast live oak. Positive controls were inoculated and untreated; negative controls were wounded (lanced) but not inoculated. cultural and natural systems.

Genetic resistance has been widely employed to protect native Port Orford cedars from introduced $P$. lateralis in California, Oregon and Washington.

At UC Berkeley, preliminary experiments by UC Berkeley forest scientist Richard Dodd, in collaboration with UC Berkeley forest pathologist Matteo Garbelotto, indicate that not all coast live oak trees are equally affected by $P$. ramorum. In an inoculation experiment performed in spring 2002, six cuttings were taken from approxiden oak death presents a serious risk to native California ecosystems and the timber industry, which necessitates a well-financed, focused research effort. Indeed, current studies indicate that there is reason to hope the disease can be brought under control. While alarming numbers of oaks have died, U.S. Forest Service pathologist Susan Frankel noted during a recent lecture at UC Berkeley that sudden oak death is a patchy disease that is "not denuding large areas."

"Species are not being driven to extinction," Frankel said. Rather, sudden oak death is "very poorly named. It's not sudden. It doesn't occur only in oaks, and it doesn't always result in death of the tree." - Janet Byron 